\title{
Agentes confidenciales y funcionarios consulares en el Golfo-Caribe. La labor de Feliciano Montenegro
}

Laura Muñoz*

INSTITUTO MORA

El artículo hace referencia a la labor de uno de los agentes secretos que trabajaron para el gobierno mexicano en la primera década de vida independiente recopilando información útil para el diseño de una estrategia oficial mexicana en la región.

$\mathbf{U}$

na vez lograda la independencia de México, los nuevos gobiernos tuvieron como tarea fundamental defender la soberanía, mantener la integridad del territorio y proteger de ataques enemigos "las desiertas y dilatadas costas del Seno mexicano", " no sólo mientras la inde. pendencia no fue reconocida, sino en

* Agradezco la colaboración de Elsa Aguilar, Delta García, Mariana García, Georgina Haw, Gerardo Hernández y Ana Lilia Nieto en la recopilación de la información utilizada en este trabajo.

${ }^{1}$ Véase Memoria, 1823, pp. 1-7. diversas ocasiones, en que aquéllas fueron amenazadas. La defensa encerraba problemas complejos: la gran dimensión del territorio que requería para su ocupación de abundantes recursos humanos y materiales; la concentración de la fuerza militar y económica en la altiplanicie meridional, flanqueada por macizos montañosos y sin ríos navegables; la extensa superficie norteña, prácticamente despoblada y acechada por vecinos codiciosos; los enormes litorales que no contaban, en general, con buenos puertos, la inexistencia de una verdadera flota naval y la insuficiencia de recursos económicos. En 
cambio, poseía terrenos deseables y áreas útiles para intentar la comunicación entre los dos océanos y se en-’ contraba, además, junto a una zona geoestratégica que constituía su puerta natural de entrada.

En un principio esa zona fue el escenario donde cobraron forma los temores frente a una España que perseveraba "en probar fortuna contra México", y donde, más adelante, se manifestaron los anhelos expansionistas de otras potencias. Por tanto, la posición mexicana hacia el Caribe, a lo largo del siglo XIX, no estuvo vinculada solamente a la amenaza española, respondió también a la presión de los intereses de otras potencias con colonias en la región, como Inglaterra o Francia y, de manera constante, a las ambiciones de Estados Unidos. De esta manera, las islas del llamado mediterráneo americano nunca fueron desatendidas por los observadores mexicanos o al servicio del gobierno mexicano, aunque Cuba ocupó, sin lugar a duda y sobre todo en el periodo que nos ocupa en este trabajo, un lugar privilegiado en esa atención. En la medida en que esa isla, su posesión y su situación geográfica, también afectaban los intereses estadunidenses, el desarrollo de las relaciones entre ella y México debe verse en un contexto más amplio en el que Estados Unidos tuvo un papel de importancia modificando -como veremos más adelanteactitudes y estrategias y, además, porque en su territorio se establecieron centros de observación y conspiración, ${ }^{2}$ entre otros lugares en Nueva Orleans,

\footnotetext{
${ }^{2}$ Véase Pi-Suñer, "Frontera", 1988, pp. 191206, y Muñoz, "Interés", 1996.
}

uno de los puntos privilegiados para observar y recabar información y en el que radicó el personaje a cuyo estudio, en un primer acercamiento, dedicamos estas páginas.

Vale la pena señalar que cuando aquí hablamos de Caribe estamos haciendo referencia al mar, el Golfo-Caribe, que hizo posible la comunicación, el tráfico (de hombres, bienes e ideas) y marcó el ritmo de la vida, así como al archipiélago que se extiende desde las penínsulas de la Florida y Yucatán hasta Venezuela. Pero como la óptica utilizada se basa en la de la correspondencia a la cancillería o al Ministerio de Guerra, no se consideran -igual que no se hace en esos documentos- los territorios del litoral, a excepción de Belicc, única frontera terrestre de México con el área caribeña.

\section{El INTERÉS DE MÉXICO EN LA INDEPENDENCIA DE CUBA}

Como la presencia española en Cuba intimidaba la independencia y la seguridad de México y se creía que la superioridad marítima de España podía "mantener a la república en agitación y embarazar al gobierno paralizando los giros" económicos y haciéndole erogar enormes gastos, ${ }^{3}$ una de las primeras preocupaciones de los gobiernos mexicanos, al iniciarse la vida independiente, fue colaborar en la emancipación de la isla para evitar que se organizaran o abastecieran en ella expe-

\footnotetext{
${ }^{3}$ Pablo Obregón a Lucas Alamán en México, 1982 , p. 53
} 
diciones militares de reconquista. ${ }^{4} \mathrm{Ya}$ a finales de 1821, en el informe elaborado por Francisco de Azcárate y presentado al emperador Agustín de Iturbide (1821-1822), se aconsejaba dar mucha atención a las islas de Cuba y Puerto Rico para prevenir las empresas hostiles que desde ellas pudieran organizarse, ${ }^{5}$ y durante los siguientes diez años hubo planes que no cristalizaron o acciones emprendidas con diversa suerte para evitar cualquier intento español de recuperar sus antiguas posesiones. ${ }^{6}$

Como parte de ese esfuerzo se dio cobijo en tierra mexicana a los patriotas cubanos y se alentó su asociación, se apoyaron expediciones militares a la Gran Antilla e, incluso, se aprobaron cantidades de dinero para "gastos secretos, ejecutivos y de grande importancia y utilidad al servicio de la república". ${ }^{7}$ No obstante, no se llegó más

\footnotetext{
${ }^{4}$ Así lo testimonia la correspondencia de los encargados de Relaciones Exteriores de México con los enviados a Estados Unidos (Pablo Obregón), a Colombia (José A. Torrens), a Nueva Orleans (Francisco Pizarro) y a Haití José I. Basadre) o los informes de los enviados secretos como Feliciano Montenegro. Véase también Chávez O., Esfuerzo, 1930, y Juárez, "Intentos", 1993, pp. 37-47.

${ }^{5}$ Dictamen presentado a la Soberana Junta Gubernativa del Imperio Mexicano por la Comisión de Relaciones Exteriores en Archivo Histórico de la Secretaría de Relaciones Exteriores de México (en adelante AHSREM), exp. C-3-33, f. 145.

${ }^{6}$ El tema es trabajado con mayor detenimiento en Muñoz, "Independencia", 1999. Se cuentan entre esos intentos los alentados por el presidente Victoria, la expedición organizada por Antonio López de Santa Anna y los planes propuestos por Mariano Michelena, Eduardo de Gorostiza y alentados por Lucas Alamán.

${ }^{7}$ Primera Secretaría de Estado, Departamento del Interior a Hacienda, 24 de julio de 1828,
}

allá. Al no hacerse realidad o al fracasar los planes españoles de reconquista, se logró la conservación de la inde. pendencia mexicana. ${ }^{8}$

Pero mientras tanto, siguiendo la tradición colonial, los nuevos gobiernos mexicanos enviaron al exterior a sus agentes, que podían ser de diferentes tipos. En misión diplomática, tenían enviados extraordinarios y ministros plenipotenciarios, agentes especiales y encargados de negocios, que se desempeñaban en las cortes europeas, frente a los gobiernos de Estados Unidos y de otros países independientes, buscando reconocimiento, empréstitos y recopilando información. Otra clase de representantes, los agentes secretos, se avecindaban en algunas islas o puntos estratégicos de tierra firme e informaban de todo lo que sucedía o se rumoraba, especialmente en la tercera década del siglo $\mathrm{XIX}$, respecto a las intenciones de reconquista, los movimientos de corsarios o el tráfico de esclavos y de otras mercancías.

Ambos tipos de agentes, oficiales y secretos, cumplían con una labor informativa importante. Al mismo tiempo que transmitían sus propias reflexiones en que analizaban la situación de México en el contexto regional, daban pautas a los responsables del Despacho

en Centro de Estudios de Historia de México CONDUMEX, fondo CCXVIII (colección de 256 documentos que reúnen los informes de Montenegro y la correspondencia con el ministro de Guerra y Marina, Manuel Gómez Pedraza).

${ }^{8}$ Autores como Rojas, "Cuba", 1999, afirman que México tenía ambiciones anexionistas o expansionistas hacia Cuba. En nuestra opinión se trata de meros discursos de una política de. fensiva. 
de Relaciones Exteriores y ofrecían elementos de gran utilidad para normar la posición mexicana. ${ }^{9}$

\section{LA labor de Feliciano Montenegro}

En el contexto de movimientos y contramovimientos en pro de la independencia o de la reconquista que se sucedieron en el Golfo-Caribe mientras no se dio el reconocimiento a la emancipación de México encontramos, entre otros, a Feliciano Montenegro como agente al servicio de la nueva república.

El coronel Montenegro era originario de Caracas y había estado al servicio de la corona española mientras vivió en lo que hoy es Venezuela. Cuando se proclamó la independencia de ésta dejó el bando realista e ingresó al insurgente, del cual se apartó posteriormente. Estuvo en Puerto Rico, en Colombia y después en Cuba. En La Habana se convirtió en secretario del capitán general y gobernador, Francisco Dionisio Vives, posición que también abandonó.

Como él mismo relata, había servido a la corona española toda su vida. Desde su niñez, dice en una de sus cartas, había estado interesado por la prosperidad y buen nombre de España, pero habiendo llegado el día de abandonarla con el mayor gusto renunciaba

igualmente al empleo de coronel que había obtenido en sus filas a fuerza de constancia y servicios distinguidos. Es bien tardía por cierto mi determinación

\footnotetext{
"Véase Villaseñor, "Labor", 1997.
}

- aclara- pues no debí esperar ver realizados los ultrajes con que acostumbra tratar (España) a los naturales de Amé. rica. $^{10}$

Él se asume como uno de ellos y en parte, creemos, su actitud pudiera explicarse como una reacción a no ser reconocido en su cargo debido a su origen americano, puesto que el rey había prohibido que se empleara para cargos militares de importancia en Cuba y Puerto Rico a "individuos hijos del país, en especial aquellos en quienes, dice la relación, se notan talentos y disposición". ${ }^{11}$ Sin embargo, hay otras versiones que señalan su salida de la isla a causa de problemas de orden personal y pasional en los que se involucraban los intereses del capitán general Vives.

Nuestro personaje aparece en 1827 en Estados Unidos y desde ahí escribe para ofrecer sus servicios al gobierno mexicano diciéndose poseedor de noticias -que "la más afortunada casualidad" puso en sus manos- relativas a movimientos españoles contra México, que va dejando saber de carta en carta, avisando también, para informar de su valía y utilidad para el gobierno mexicano, que las autoridades españolas lo buscaban en Colombia creyendo que hacia allá se habría dirigido y donde aprovecharían "sus conocimientos y relaciones no sólo con respecto a Cuba,

${ }^{10}$ Montenegro al presidente de la república, 6 de marzo de 1827 en Archivo General de la Nación (en adelante AGN), fondo Guerra y Marina, caja 75, s.n. (los tres documentos citados con esta fecha son diferentes).

${ }^{11}$ Ibid. 
sino también a aquellas islas [donde] había conspirado". ${ }^{12}$

De Filadelfia fue a Nueva Orleans para trasladarse a México, donde permaneció un año antes de regresar nuevamente a Nueva Orleans desde donde cumpliría su papel de agente del gobierno mexicano. La Secretaría de Guerra y Marina fue la encargada de contratar sus servicios, sin precisar inmediatamente a dónde enviarlo, indecisa entre Panzacola, Nueva Orleans o

el paraje que le parezca más a propósito para desempeñar los puntos a que se contraen sus ofrecimientos, disfrutando 2000 pesos anuales pagaderos en Veracruz y 400 en la ciudad de México para la educación de su hijo,

pero a cuenta de Relaciones Fxteriores, donde existía una partida especial para esos gastos. ${ }^{13}$ Según una copia de un documento del 5 de noviembre de 1827, Montenegro prestaría varios servicios después de establecerse en la Luisiana o Florida. El principal sería enterarse e informar de cuanto se tramara en La Habana contra el continente, así como del contenido de la correspondencia reservada de Madrid; periódicamente haria reportes acerca del tamaño de la fuerza acantonada en la isla de Cuba y de las nuevas obras de fortificación, haría planos de las fortalezas así como de la isla en general,

${ }^{12}$ Montenegro al secretario de Guerra, 6 de marzo de 1827 en ibid.

${ }^{13}$ Secretaría de Guerra y Marina al oficial mayor encargado del Ministerio de Relaciones Exteriores, México, 15 de febrero de 1828 en ibid. extendería las ramificaciones de los militares y paisanos comprometidos a trabajar por la independencia [...] promoveria cualquier circunstancia favorable [para lograrla, y] daría conocimiento de los progresos o atrasos de la marina española. ${ }^{14}$

Como Cayetano López, su seudónimo por un tiempo, ${ }^{15}$ aconsejaba que el enemigo fuera vigilado con suma precaución y cuidado, al observar-durante uno de sus viajes- el descuido que había en la vigilancia y la confianza que privaba en las costas del Seno mexicano. Varias veces recomendó reforzar la seguridad y propuso una red eficiente y segura en la que participaran los agentes secretos en combinación con los cónsules y enviados extraordinarios y ministros plenipotenciarios como Francisco Pizarro Martínez (en Nueva Orleans) y Pablo Obregón (en Washington).

Entre sus actividades podía proponer la incorporación de otros agentes, por ejemplo en Santo Domingo, para "que entablare y adelantare buenas relaciones con la parte oriental de Cuba" o en Jamaica, ${ }^{16}$ sin olvidar que Nueva Orleans, ${ }^{17}$ "el foco de las intrigas de los españoles contra México", ${ }^{18}$ era uno de

${ }^{14}$ Ministerio de Guerra y Marina, 5 de noviembre de 1827 , enviada el 15 de febrero de 1828 en ibid.

${ }^{15}$ Montenegro, "Extracto del diario de $\mathrm{mi}$ viaje desde Filadelfia a Jalapa atravesando los Estados Unidos del Norte por el interior y costeando el territorio de la república mexicana desde Tabasco a Veracruz", 19 de septiembre de 1827 en ibid.

${ }^{16}$ Montenegro a Gómez Pedraza, 16 de febrero de 1828 en ibid.

${ }^{17}$ Montenegro al secretario de Guerra, 6 de marzo de 1827 en ibid.

${ }^{18}$ Como lo describiría, en 1829 , José María 
los lugares que debería estar siempre cubierto

Es también de suma importancia -decía- que con anticipación sitúe el gobierno un agente secreto en Santo Domingo que sin entenderse por ahora con la república tome conocimiento y forme relaciones íntimas con el país con respecto a las personas que trafican en la parte oriental de Cuba, a fin de aprovechar su servicio cuando llegue la ocasión advirtiendo a V. E. que en Filadelfia están prontos dos cubanos para trasladarse a Jamaica y los Caymanes cuando se les prevenga y de cuyos nombres daré a V. E. conocimiento cuando me lo pida a fin de que el señor Pablo Obregón, o el señor cónsul de la república en la mismo ciudad, que los conocen personalmente, les den las instrucciones del caso en la manera que sea conveniente. En Veracruz existe otro inglés de confianza, expulsado de Santiago de Cuba, que puede hacer muy buenos servicios. ${ }^{19}$

Insistía en que se buscara a personas de mucha confianza para que colaboraran con el gobierno mexicano en una empresa tan delicada como era la de apoyar la emancipación de Cuba y reiteraba que no era sólo la urgencia y seguridad la que se recomendaba en la remisión de la correspondencia, sino que igual importancia revestía el que aun el conductor ignorara el origen de la fuente. ${ }^{20}$ Los sobres se sobrecarta.

Montoya, encargado de negocios de México en Estados Unidos.

${ }^{19}$ Montenegro al secretario de Guerra y Marina, México, 13 de octubre de 1827 en AGN, fondo Guerra y Marina, caja 75, s.n.

${ }^{20}$ Montenegro al presidente de la república, reservada, 6 de marzo de 1827 en $i b i d$. ban viniendo de Nueva Orleans al oficial mayor del Ministerio de Relaciones Exteriores de esta república, pero iban dirigidas al supremo gobierno. Sin embargo, Montenegro se dedicaba fundamentalmente a todo lo relativo a favorecer la emancipación de la isla de Cuba, ${ }^{21}$ pues mientras no fuera independiente, la suerte de México no podría considerarse absolutamente asegurada, ${ }^{22}$ idea que era compartida por representantes de diferentes facciones políticas.

No escapó a los análisis de Montenegro, por supuesto, la importancia de Cuba para la seguridad e interés de México. En uno de sus informes podemos descubrir una muestra de una percepción geopolítica ${ }^{23}$ cuando el autor expone las razones por las cuales México no debía descuidar la situación en la isla, situada a la entrada del Golfo de México

por donde salen todos los productos de una parte de la costa firme, de Honduras, de los estados que componen esta federación [la mexicana] y de los de la Unión Angloamericana que bajan por el Mississippi y aun muchos de los de Jamaica,

\section{y recuerda que}

${ }^{21}$ Montenegro al secretario de Estado y del Despacho de Guerra y Marina, 28 de septiembre de 1827 en ibid.

${ }^{22}$ Cubanos al secretario de Estado y del Despacho de Guerra y Marina, 20 de octubre de 1827, en ibid.

${ }^{23}$ Uso el término geopolítica -aunque en la época no fuera usado- en cuanto indica un enfoque que da significación a la ubicación geográfica y a su influencia en el desarrollo de una política exterior. 
es uno de los puntos del globo cuya importante posición deben y han ambicionado siempre las naciones comerciantes, porque conocen cuánto vale su situación para dominar exclusivamente el tráfico de la mayor y más rica parte de la América. ${ }^{24}$

e incluye, entre otros, datos acerca de la población, la economía y los recursos militares.

En medio de esos informes acerca de la riqueza de la isla, va introduciendo la información necesaria para preparar una invasión militar -información que se sugiere sea transmitida al comandante David Porter, encargado de la escuadra mexicana que recorría las aguas del Golfo-Caribe procurando dañar el comercio español. En sus notas, nuestro agente describe con detalle las costas de la isla, sus embarcaciones, la ubicación de los apostaderos de fuerzas útiles, cayos, entradas y salidas peligrosas o apropiadas, los puertos de poco calado y advierte que "la empresa de ocupar la isla de Cuba es no sólo peligrosísima, sino también difícil de llevar a cabo". 25 Sin embargo, Montenegro confiado en que ésta se lograría ofrece, en otras cartas, varios planes para llevarla a cabo. ${ }^{26}$

Feliciano Montenegro, a través de su correspondencia reservada, muy reservada y, en algunos casos cifrada, llevó a cabo una excelente labor de información, de mayo de 1827 hasta casi

\footnotetext{
${ }^{24}$ Montenegro, "Idea general de la isla de Cuba", reporte, 28 de septiembre de 1827 , en AGN, fondo Guerra y Marina, caja 75, s.n.

${ }^{25}$ Ibid. ibid.

${ }^{26}$ Montenegro, 7 de noviembre de 1827 , en
}

finales de $1829 .{ }^{27}$ La región que observaba: "los puertos y territorios circuidos por el mar de las Antillas y del rico Seno mexicano", ${ }^{28}$ era muy amplia, de hecho, podría dividirse en varias subregiones en las que destacan los informes de las áreas comprendidas en los triángulos Campeche-Habana-Nueva Orleans y Caracas-islas de BarloventoNueva Orleans.

Por su contigüidad, Puerto Rico merecía la misma atención que Cuba, pero en México se pensaba que Colombia debería apoyar la independencia de esa isla, mientras que a México le correspondía ayudar a la independencia de "la mejor de las Antillas", siendo "esta naciôn la única ejecutora de la empresa". ${ }^{29}$ Algunos autores han pretendido ver ambiciones expansionistas en este interés por intervenir en la independencia antillana ${ }^{30} \sin \mathrm{em}$ bargo, el origen de esta actitud, según revelan los documentos, respondía exclusivamente a la necesidad de contribuir a procurar seguridad al nuevo país. ${ }^{31}$ Las ideas acerca del "engrande-

${ }^{27}$ Ibid.

${ }^{28}$ Feliciano Montenegro al secretario de Estado y del Despacho de Guerra y Marina, 17 de octubre de 1827 en ibid.

${ }^{29}$ Ministerio de Guerra y Marina a Feliciano Montenegro, 24 de julio de 1828 , muy reservada, en ibid.

${ }^{30}$ Rojas, "Independencia", 1992, pp. 79-110.

${ }^{31}$ Así lo expresa Zavala, Ensayo, 1981, p. 295; Bocanegra, Memorias, 1892, tomo II, y una nota en El Veracruzano Libre, Veracruz, 9 de octubre de 1827, coincide en esa visión: "Poseyendo México este respetable antemural sería diferente su suerte y su situación política variaria muy en su provecho: probablemente Cuba sería el teatro de las guerras que México tuviese que sostener contra la Europa, como que alli 
cimiento y seguridad de la república" están expresadas constantemente en las notas enviadas.

En 1829, Feliciano Montenegro seguía "sirviendo con mucho celo al gobierno de México", según palabras del cónsul español en Nueva Orleans. ${ }^{32}$ En ese año, el último de sus servicios, comunicó la veracidad de la expedición del brigadier Isidro Barradas, detallando la cantidad de hombres y especificando el supuesto lugar de desembarco. Después de eso dejó de prestar sus servicios al gobierno mexicano. Jaime Delgado, autor de una de las historias de las relaciones entre México y España en el siglo XIX, considera que la causa fue la falta de fondos del erario mexicano, pero en nuestra opinión se debió, o bien a que sus servicios fueron sustituidos por los del nuevo agente mexicano, el coronel José Ignacio Basadre, quien fue comisionado para firmar un acuerdo de cooperación entre el gobierno haitiano y el de México o, y ésta es la explicación por la que me inclino más, a que el gobierno mexicano abandonó cualquier plan de intervención en la independencia cu-

están sus puertas y no podría prescindirse de ella para entrar al continente, ni sería prudencia encerrarse en un saco o seno rodeado de enemigos por todas partes, a dos mil leguas de sus recursos. $Y$ ies poca ventaja tener un país separado por los mares en donde rechazar los esfuerzos de las armas enemigas conservando el continente en la quietud, la tranquilidad y la seguridad?"

${ }^{32}$ Citado en Delgado, España, 1953, t. 4, p. 355. Francisco Tacón creía que Montenegro había dado información importante al gobierno mexicano acerca de los planes de la capitanía general de Cuba en contra de la nueva república, véase Franco, Documentos, 1961, p. 340. bana ante la presión de las potencias del momento interesadas en que Cuba no dejara de ser posesión española.

Para México, Cuba representaba el bastión de su seguridad, pero para los poderes imperiales era el punto estratégico por excelencia para controlar las comunicaciones que entraban y salían del Atlántico. Por eso, para Estados Unidos era importante evitar que algu. na de las potencias europeas se apoderara de Cuba, o que lo hicieran México o Colombia, que no podrían defenderla de esas potencias. ${ }^{33}$ Entonces, la posición que mantuvieron desde 1825 fue la de apoyar la tutela española en la isla y declarar reiteradamente que estarían complacidos con la permanencia de esa situación. Preveían que la independencia antillana no sería posible porque, por su debilidad, Cuba terminaría anexada a otro país o bajo la tutela de alguna potencia europea. En cuanto a Gran Bretaña y a Francia, ambas compartieron el deseo de Estados Unidos de que la importante colonia española permaneciera en poder de su metrópoli. ${ }^{34} \mathrm{~A}$ raíz de la misión de Basadre, Gran Bretaña presionó para que México abandonara esa intención "porque nunca consentiría que se hostilizara por medios tan inicuos a la España". 35

En 1836, al obtener el reconocimiento español a su independencia, México cambió inmediatamente su posición frente a Cuba. Una vez firmado el

${ }^{33}$ Pablo Obregón a Lucas Alamán, 8 de enero de 1828, en AHSREM, Archivo de la limbajada de México en Estados Unidos, t. I, fs. 23-28.

${ }^{34}$ Chávez, Esfuerzo, 1930, p. 6 y 64.

${ }^{35}$ Franco, Documentos, 1961, p. 150. 
tratado de paz y amistad con España, la joven república defendió, ante todo, la neutralidad y la no intervención en los asuntos domésticos cubanos, al mismo tiempo que dio paso a una nueva estrategia, la diplomática, que estuvo a cargo de los cónsules mexicanos en la isla.

\section{CONCLUSIONES}

Por diversas razones los estudios que abordan las relaciones de México con el mundo en el siglo Xxx, han dado prioridad a las establecidas con Estados Unidos y con Centroamérica. Recientemente se ha empezado a vislumbrar el lugar que ocupó el Caribe en la concepción de una política exterior, entendida como defensa de los intereses nacionales en el ámbito internacional, en tanto constituía lo que apenas en la década pasada se reconoció oficialmente como tal, su tercera frontera. ${ }^{36}$ El interés oficial de México por la región caribeña se manifestó en dos ámbitos: el político y el económico. El primero, al que en uno de sus aspectos nos referimos en estas páginas, estaba relacionado con la necesidad de contar con una zona de frontera, amortiguadora, en la que también, como en tierra firme, se definía la seguridad nacional. El segundo, tenía que ver con la urgencia de mantener despejadas las vías de tráfico marítimo y comercial.
El Golfo-Caribe como el escenario en el que, entre otros, numerosos agentes secretos representantes de los intereses de las diversas potencias del momento recabaron información útil para diseñar las estrategias ofensivas, defensivas y políticas de esos poderes en la batalla por el dominio de la región ha sido bien descrito por José Luciano Franco en varios de sus libros. ${ }^{37}$ En ese escenario no faltaron los agentes que al servicio del gobierno mexicano enviaban reportes confidenciales, incluso cifrados, contribuyendo así a que la nueva nación normara su proceder en el ámbito internacional. Para México era una manera sistemática de recabar información ${ }^{38}$ probablemente heredada de España, pero practicada de forma generalizada por las potencias del momento para las que los informes confidenciales eran la regla. Esos agentes podían ser comerciantes, viejos militares, viajeros o tener otra profesión.

El ejemplo de Feliciano Montenegro nos permite conocer la labor que desempeñaban esos agentes secretos al servicio de los gobiernos con intereses en la región. Falta mucho por investigar alrededor de este personaje, acerca de su influencia en el gobierno mexicano y, sobre todo, si su labor se dedicaba a un solo gobierno o si él, como otros agentes, se desempeñaba en realiclad como agente doble al servicio de España y de los gobiernos independientes.

\footnotetext{
${ }^{36}$ Por ejemplo, véase Muñoz, "Interés", 1996, y Pulido, "Aproximaciones", 1997.
}

${ }^{37}$ Franco, Batalla, 1965, vol. 2. 21.

${ }^{38}$ Véase Jiménez Codinach, Gran, 1991, p. 
ARCHIVOS

AGN Archivo General de la Nación.

AHSREM Archivo Histórico de la Secretaría de Relaciones Exteriores de México.

Centro de Estudios Históricos CONDUMEX

\section{BIBLIOGRAFÍA}

-Bocanegra, José María, Memorias para la bistoria de México independiente 18221846 , Imprenta del Gobierno Federal en el Ex Arzobispado, México, 1892, t. II.

-Chávez O., Luis, Un esfuerzo de México por la independencia de Cuba, SRE, México, 1930 (Archivo Histórico Diplomático).

-Delgado, Jaime, España y México en el siglo XIX, Consejo Superior de Investigaciones Científicas, Madrid, 1953.

-Franco, José Luciano, Documentos para la bistoria de México, Publicaciones del Archivo Nacional de Cuba, La Habana, 1961.

La batalla por el dominio del Caribe y el Golfo de México. Revoluciones y conflictos internacionales en el Caribe 1789-1854, Academia de Ciencias, La Habana, 1965, 2 vols.

-Jiménez Codinach, Guadalupe, Gran Bretaña y la independencia de México, 1808-1821, Fondo de Cultura Económica, México, 1991.

-Juárez, Yolanda, "Dos intentos de apoyo a la independencia de Cuba desde México" en El Caribe en la encrucijada de su bistoria, UNAM, México, 1993 (Panoramas de Nuestra América, 8).
-Memoria que el secretario de Estado y del Despacho de Marina presenta al soberano Congreso Constituyente mexicano leida en sesión pública de 13 de noviembre de 1823, Imprenta del Águila, México, 1823.

-México y Cuba, dos pueblos unidos en la bistoria, Centro Jorge L. Tamayo, México, 1982.

-Muñoz, Laura, "El interés geopolítico de México por el Caribe como espacio regional en el siglo XIX", tesis de doctorado, FCPYS-UNAM, México, 1996.

ba en la defena independencia de CuOporto, 1999 (por publicarse).

-Pi-Suñer, Antonia, "La frontera del Golfo: México ante la primera guerra de independencia cubana 1868-1878" en Cuadernos de Investigación, UNAM-ENEP Acatlán, 1988 (Programa de Investigación, 8).

-Pulido, Gabriela, "Aproximaciones a la política exterior del porfiriato. La gestión diplomática de Andrés Clemente Vázquez en Cuba", tesis de licenciatura, FFYL-UNAM, México, 1997.

-Rojas, Rafael, "La independencia de Cuba desde México" en Anuario de la Academia Mexicana de la Historia, 1992.

- "Cuba mexicana. Historia de una anexión imposible, 1810-1910", tesis de doctorado, El Colegio de México, México, 1999.

-Villaseñor B., José Miguel, "La labor informativa de la legación mexicana de Washington, 1822-1844", tesis de licenciatura, FFYL-UNAM, México, 1997.

-Zavala, Lorenzo de, Ensayo bistórico de las revoluciones en México desde 1808 basta 1830, t. I, SRA-CEHAM, México, 1981. 